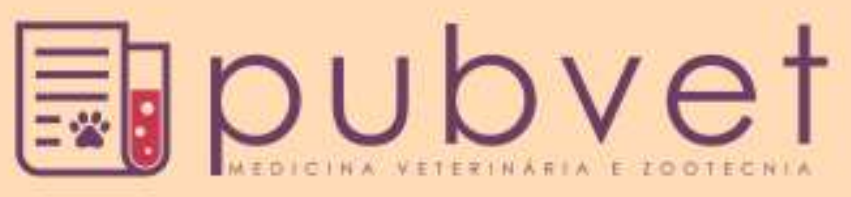

HTTP://DX.DOI.ORG/10.22256/PUBVET.V111N3.285-289

\title{
Prolapsos em pequenos animais
}

Tanara Raquel de Oliveira da Silva ${ }^{1}$, Camila Frantz Heck ${ }^{1}$, Camila Simões Veloso ${ }^{1}$, Franciélli Pizzuti Nascimento ${ }^{1}$, Larissa Tais Vier ${ }^{1}$, Gabriele Maria Callegaro Serafini2**

${ }^{\text {I} A l u n a ~ d a ~ U n i v e r s i d a d e ~ R e g i o n a l ~ d o ~ N o r o e s t e ~ d o ~ E s t a d o ~ d o ~ R i o ~ G r a n d e ~ d o ~ S u l ~-~ U n i j u i ́, ~ D e p a r t a m e n t o ~ d e ~ E s t u d o s ~ A g r a ́ r i o s ~-~ D e a g, ~ I j u i ́-R S, ~}$ Brasil e-mail: tanarasilvazinha@yahoo.com.br, camiheck@hotmail.com, mila-veloso@hotmail.com, fran.pizzuti@hotmail.com, larissavier@hotmail.com

${ }^{2}$ Professora da Universidade Regional do Noroeste do Estado do Rio Grande do Sul - Unijuí, Departamento de Estudos Agrários - Deag, Ijuí-RS, Brasil e-mail: gabrieleserafini@yahoo.com.br

*Autor para correspondência.

RESUMO. Objetiva-se com esta revisão, descrever as principais características de três tipos de prolapsos comumente observados na rotina clínico-cirúrgica de pequenos animais: prolapso de vagina, útero e reto. São afecções que podem ser confundidas entre si e que dependendo de cada situação possui um tipo de tratamento distinto, variando desde apenas a redução manual do conteúdo até a ressecção do tecido prolapsado.

Palavras chave: cães, gatos, protrusão, ressecção

\section{Prolapses in small animals}

ABSTRACT: The objective of this review is to describe the main characteristics of three types of prolapses commonly observed in the clinical-surgical routine of small animals: prolapse of the vagina, uterus and rectum. They are conditions that can be confused with each other and depending on each situation has a different type of treatment, ranging from only manual reduction of the content to resection of the prolapsed tissue.

Keywords: dogs, cats, protrusion, resection

\section{Prolapsos en pequeños animales}

RESUMEN. Con esta revisión el objetivo es describir las principales características de tres tipos de prolapsos comúnmente observados en la rutina clínica y quirúrgica de pequeños animales: prolapso vaginal, útero y recto. Son trastornos que pueden ser confundidos entre si y dependiendo de cada situación hay un tipo diferente de tratamiento, que puede variar desde una simple reducción manual del contenido hasta la resección del tejido prolapsado.

Palabras clave: perros, gatos, protrusión, la resección

\section{Introdução}

O prolapso em geral é caracterizado pelo deslocamento de órgãos que estão na sua posição anatômica, para o exterior das cavidades que nelas se localizam. Estes podem ser classificados em prolapso de vagina, útero e reto, sendo esses os mais susceptíveis em animais de todas as espécies (Hedlund, 2008).

O prolapso vaginal tem mais ocorrência durante o estro e proestro pelo aumento de estrógeno na circulação (Hedlund, 2008). A vagina apresenta-se com edema, resultando em uma congestão venosa e manchas teciduais com aparência de rosca, podendo aparecer úlceras (Birchard and Sherding, 2008).

O prolapso uterino é uma condição rara; porém pode ocorrer durante ou vários dias após a parição, com eversão e protrusão de uma porção do útero pela cérvix para dentro da vagina, tendo mais ocorrência em gatas (Sicard and Fingland, 2008b). Os mesmos autores salientam que o prolapso pode 
romper o ligamento largo e a artéria uterina, e a hemorragia pode levar ao choque hipovolêmico se não controlada a tempo.

O prolapso retal é caracterizado pela perda do tônus do esfíncter, em decorrência do afrouxamento do tecido conectivo submucoso ou devido a uma falha no sistema suspensório do reto (Wintzer, 1990).

O presente trabalho tem como objetivo revisar as principais considerações sobre essas afecções, desde duas causas, diagnóstico até as opções de tratamento.

\section{Prolapso vaginal}

A vagina se torna edemaciada e hiperplásica, e às vezes a variação é tão drástica que o tecido vaginal se projeta para o exterior da vulva. Ocorrem exclusivamente em períodos de estimulação estrogênica, e por este motivo somente são identificadas durante estro e proestro (Hedlund, 2008, Nelson and Couto, 2015). É comum a reincidência no decorrer de cada estro; porém a severidade e intensidade variam (Nelson and Couto, 2015). Raças braquiocefálicas, incluindo Boston Terrier e Boxer, são mais predispostas que outras raças (Birchard and Sherding, 2008). Embora raro, é comum em cães de raças de grande porte e em cadelas jovens durante um dos três primeiros ciclos estrais. É raro em gatas (

Sinais clínicos como edema e protrusão da mucosa vaginal resultam em uma congestão venosa e manchas teciduais com aparência de rosca (Birchard and Sherding, 2008). Estes tecidos são friáveis podendo facilmente apresentar úlceras (Nelson and Couto, 2015). Hedlund (2008) relata a lambedura da região perineal, polaquiúria, disúria e edema perineal também como sinais clínicos da doença.

O diagnóstico se baseia no exame físico, que revela uma estrutura tubular ou em forma de rosca que se projeta pela vulva (Sicard and Fingland, 2008a, Birchard and Sherding, 2008),. A massa deve ser bem examinada para determinar origem, tamanho e expansão, e a localização do lúmen vaginal (Hedlund, 2008, Nelson and Couto, 2015). O histórico indica se o animal está no proestro ou estro, caso não ocorrer pode-se fazer uma citologia vaginal que confirmará o estágio do ciclo (Nelson and Couto, 2015).

A palpação vaginal demonstra à origem da massa que é ventral à vagina e cranial ao orifício uretral (Nelson and Couto, 2015, Birchard and Sherding, 2008), todas as outras áreas da vagina apresentam-se normais (Nelson and Couto, 2015). Nelson and Couto (2015) classificam o prolapso em três tipos, sendo assim o prolapso de tipo I geralmente é muito liso, brilhante e rosa-pálido e opalescente devido ao edema, o prolapso de tipo II é ressecado, opaco e enrugado e a desenvolvimento de fissuras e úlceras, e o prolapso de tipo III envolve toda circunferência da vagina. $\mathrm{O}$ fluxo urinário raramente é impedido.

O prolapso de vagina tem como diagnóstico diferencial o edema de vagina e neoplasia vaginal (Nelson and Couto, 2015, Birchard and Sherding, 2008). Segundo Nelson and Couto (2015) para diferenciar prolapso vaginal de edema e neoplasia vaginal deve-se introduzir uma sonda uterina entre a tumefação e a parede vaginal. Observa-se a passagem da sonda por entre a vagina, quando a sonda passar normalmente é característico de tumor ou edema vaginal. No prolapso, a sonda não consegue seguir em frente e atinge uma bolsa cega. Para Birchard and Sherding (2008) pode-se ainda realizar um aspirado por agulha fina para propiciar informações citológicas para $\mathrm{o}$ diagnóstico de neoplasia. Conforme a literatura, o tratamento é de suporte, pois, o edema e a hiperplasia se resolvem espontaneamente quando a fase folicular do ciclo e a produção ovariana de estrógeno cessam. Para isso, recomenda-se a ovariohisterectomia $(\mathrm{OVH})$, a qual também previne a recidiva já que o animal não terá mais ciclo estral (Sicard and Fingland, 2008a). O tecido edematoso deve ser protegido contra traumas e infecções podendo ser utilizados antibióticos tópicos ou cremes antibióticos esteroidais, além da limpeza do tecido com solução salina e água morna e uso do colar elisabetano para evitar a automutilação (Nelson and Couto, 2015). Se a protrusão não for circunferencial, o prolapso vaginal regredirá assim que diminuir a influência do estrogênio. $\mathrm{O}$ ciclo estral pode ser encurtado administrando-se hormônio liberador de gonadotropina $(\mathrm{GnRH})$ ou gonadotropina coriônica humana (HCG) para induzir a ovulação (Hedlund, 2008).

Para Birchard and Sherding (2008), além de manter os tecidos expostos limpos, úmidos e lubrificados, se possível, deve-se fazer a reposição manual de tais tecidos. Caso seja necessário, podese aplicar solução hiperosmótica (dextrose 50\%) após a limpeza para ajudar na redução do edema. Para massas grandes e protruídas, Hedlund (2008) recomenda a episiotomia para facilitar a redução e 
sutura vulvar com pontos em Wolff com fio inabsorvível 2.0 a fim de evitar um novo prolapso até que o tecido edemaciado regrida.

A ressecção do tecido sem $\mathrm{OVH}$ não é recomendada pela significativa hemorragia causada, além de não prevenir a reincidência. A mesma só deve ser feita quando o tecido está intensamente danificado ou necrótico (Hedlund, $\underline{2008}$, Nelson and Couto, 2015). Para tal, realizase uma episiotomia para expor a massa, coloca-se uma sonda uretral e secciona-se na base do tecido edemaciado. A hemorragia deve ser controlada com pressão, ligaduras e eletrocoagulação. Posteriormente, aproximam-se as bordas da mucosa com suturas interrompidas ou contínuas com fio absorvível 3.0 ou 4.0 ((Hedlund and Fossum, 2008).

Nelson and Couto (2015) comentam que a hereditariedade do prolapso ainda é desconhecida, mas acredita-se ser de natureza familiar. Portanto, os animais que apresentam o prolapso vaginal não podem ser utilizados para reprodução (Hedlund, $\underline{2008)}$.

\section{Prolapso uterino}

O prolapso uterino é a eversão e protrusão de uma porção do útero pela cérvix para dentro da vagina durante ou próximo ao parto (Hedlund, 2008). Um corno ou todo o útero pode sofrer prolapso durante o trabalho de parto prolongado ou até 48 horas após o mesmo, quando a cérvix apresenta-se extremamente dilatada (Stone, 2007).

Sinais clínicos como agitação, postura anormal, dor, inchaço perineal, lambeduras e disúria são comuns nos casos de prolapso uterino. O diagnóstico é feito basicamente por exame físico, onde a mucosa evertida pode exteriorizarse pela vulva ou ser digitalmente palpada dentro da vagina. Para o diagnóstico diferencial deve-se pensar em prolapso vaginal e tumor de vagina, sendo o prolapso uterino e tumor vaginal difíceis de diferenciar do prolapso vaginal (Hedlund, 2008).

Segundo Sicard and Fingland (2008a), as fêmeas podem ser clinicamente estáveis ou apresentar desequilíbrio metabólico discreto a grave. E antes do tratamento devem-se corrigir as anormalidades hidroeletrolíticas ou ácido-base no animal. Entretanto, vale salientar que o prolapso uterino pode romper o ligamento largo e a artéria uterina e a hemorragia prolongada pode levar ao choque hipovolêmico (Hedlund and Fossum, 2008).
Para o tratamento, necessita-se avaliar a viabilidade do útero prolapsado. Dentre as opções, incluem-se a redução manual do prolapso, redução manual e ovário-histerectomia imediata, redução interna mediante celiotomia e amputação externa do útero. Após redução manual, pode ser necessária ovário-histerectomia, caso o útero esteja desvitalizado. Recomenda-se amputação externa do órgão apenas quando não é possível recolocá-lo na posição normal (Sicard and Fingland, 2008b).

No tratamento para a redução manual é necessário limpar o útero e envolvê-lo em compressa estéril, embebida em solução de dextrose hipertônica, o qual pode ajudar na redução do edema. Com os dedos tenta-se reduzir o prolapso, caso não houver sucesso deve-se preparar o períneo e o útero para cirurgia de episiotomia. Se ainda não for eficaz, deve-se fazer a redução interna mediante celiotomia, ou até mesmo a amputação externa do órgão exposto (Hedlund, 2008, Sicard and Fingland, 2008b). O prolapso de útero raramente recidiva após sua redução, sendo que já foi relatada prenhez bemsucedida de uma gata seis meses pós a redução de prolapso uterino (Stone, 2007).

Quando não se consegue reduzir o útero, realiza-se a amputação do mesmo, seguida de redução apenas do coto. Para isso, realiza-se uma incisão na porção cranial do corpo uterino, próximo à vulva. As extremidades craniais dos cornos uterinos ficam visíveis. Então, tracionamse suavemente os cornos para tentar expor os ovários. Se possível a artéria ovariana é ligada proximalmente ao ovário. Se os ovários não puderem ser vistos, cada corno uterino será seccionado entre duas ligaduras. As artérias uterinas são ligadas e seccionadas, e o útero é seccionado e suturado com fios absorvíveis com padrão simples separado. Assim, o coto uterino poderá ser reduzido pela vagina. Os ovários remanescentes são removidos por meio de celiotomia (Stone, 2007). Complicações pósoperatórias não são comuns em redução manual ou amputação externa ((Hedlund, 2008, Sicard and Fingland, 2008b).

\section{Prolapso retal}

O prolapso retal é a inversão de uma ou mais camadas do reto através do ânus (Cunha et al., 2015). Dependendo das estruturas envolvidas, o prolapso retal pode ser parcial ou completo. O parcial é caracterizado quando ocorre somente a 
protrusão da mucosa retal, já no completo ocorre a invaginação de duas camadas do reto, podendo englobar a junção anorretal do canal anal (Ettinger and Feldman, 2004).

O prolapso retal tem maior predisposição em animais jovens, de qualquer raça, idade ou sexo (Wachask, 2002). Sua etiologia está comumente relacionada às causas digestivas, sendo observado comumente em animais com diarreia, tenesmo graves (Cunha et al., 2015) e endoparasitismo (Wachask, 2002).

Os sinais clínicos consistem na projeção de massa tubular vermelho escuro e de aparência úmida pelo ânus (Figura 1) podendo ser muitas vezes de tamanhos variáveis. Outros sinais clínicos que são menos perceptíveis é a dificuldade de defecar quando o animal tem exteriorização, podendo ter ou não presença de sangramento, o animal tenta lamber o prolapso, podendo sentir dor ao tocar no abdômen e ainda muitos deles podem apresentar agressividade (Ettinger and Feldman, 2004).

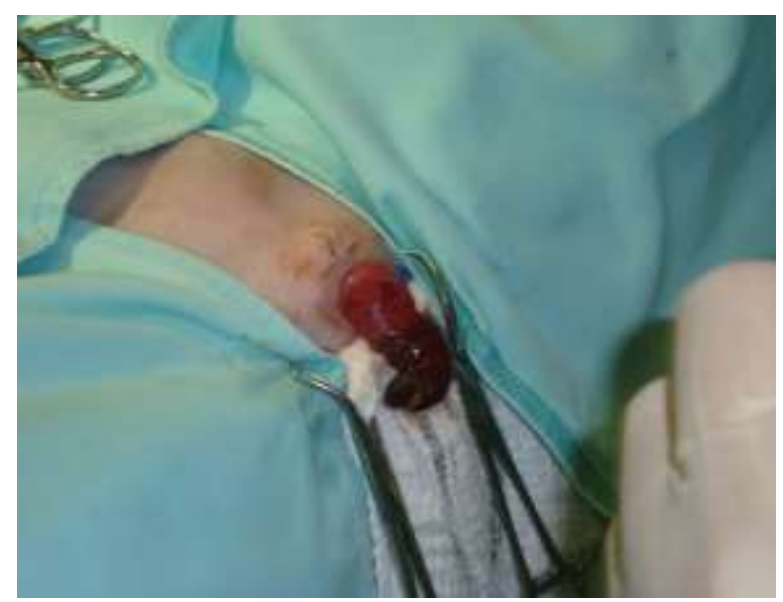

Figura 1. Prolapso de reto em gata. Observar massa tubular com coloração vermelho escura e área distal desvitalizada.

O diagnóstico é efetuado mediante apresentação clínica como predisposição da doença e histórico além do exame físico diante da visualização da massa tubular que se projeta pelo ânus, de forma e comprimentos variáveis. O principal diagnóstico diferencial é a intussuscepção ileocólica que apresenta protrusão de reto. Na intussuscepção é possível inserir um dedo ou sonda ao longo da lateral da massa exteriorizada, o mesmo não ocorre no prolapso retal (Ettinger and Feldman, 2004, Hedlund and Fossum, 2008).

De modo geral, prolapsos retais com boa viabilidade tecidual podem ser tratado por redução manual, seguida de sutura em Bolsa de tabaco no ânus (Slatter, 2007). Para esse procedimento, deve-se lavar o conteúdo prolapsado com solução salina morna, massageá-lo e lubrificá-lo com gel hidrossolúvel (Hedlund and Fossum, 2008) e por fim, aplicar pressão suave para que o mesmo se reduza. Em seguida, aplica-se sutura em Bolsa de tabaco, a qual deve permanecer no local por três a cinco dias (Slatter, 2007). A Bolsa de tabaco deve ser justa o suficiente para o reto não prolapsar novamente, mas sem interferir com a passagem de fezes macias (Hedlund and Fossum, 2008). Nesse sentido, durante esse período, o animal deve ser alimentado com dieta contendo baixo teor de resíduos e laxantes, como lactulose (Slatter, 2007). Adicionalmente, pode-se realizar anestesia epidural a fim de evitar mais esforço do animal durante a defecação e consequentemente um novo prolapso (Hedlund and Fossum, 2008).

Quando o tecido retal estiver traumatizado ou desvitalizado, recomenda-se a ressecção e anastomose. Para tal, pode-se aplicar um tubo de ensaio no reto para ajudar na colocação das suturas e também para prevenir contaminação fecal no local da cirurgia. Em seguida, aplicam-se quatro pontos de reparo atravessando toda a circunferência do tecido. Na distância de um a dois centímetros do ânus, o tecido prolapsado é resseccionado $\mathrm{e}$ as duas extremidades são anastomosadas com apenas uma linha de sutura com isolado simples atravessando todas as camadas, com fio sintético absorvível monofilamentar (Figura 2). Após completar a sutura, os pontos de reparo são removidos e o prolapso reduzido manualmente(Slatter, 2007).

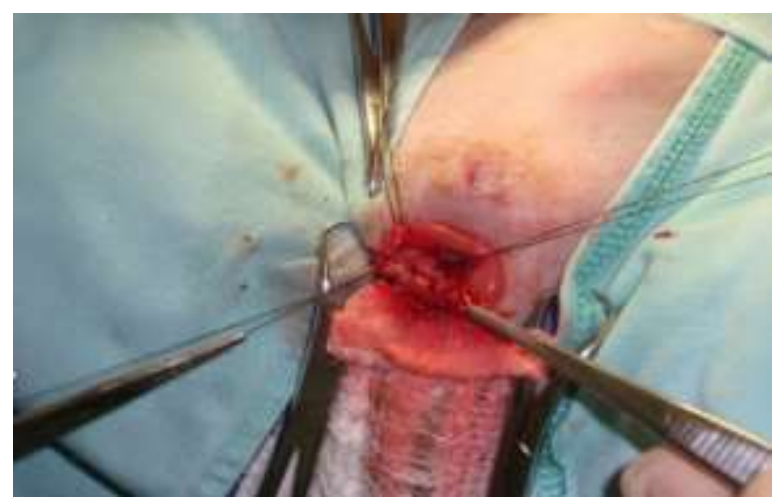

Figura 2. Ressecção e anastomose em paciente felina acometida por prolapso de reto com tecido desvitalizado. Notar os pontos de reparo, fundamentais para a manipulação do segmento retal, e suturas isoladas simples, atravessando todas as camadas, em plano único.

Quando o prolapso vem a recidivar, recomenda-se a colopexia, a qual consiste em uma secção elíptica de $5 \mathrm{~mm}$ por $1 \mathrm{~cm}$ de peritônio que 
é retirado da parede abdominal e outra área correspondente também é removida da serosa do cólon, onde as superfícies são integradas e suturadas com cinco ou seis pontos simples desprendidos com fio 3.0 náilon ou prolipropileno, sendo esta realizada na parede abdominal esquerda com uma leve tração do cólon (Wachask, 2002).

É importante salientar que a causa do prolapso retal também deve ser corrigida para prevenir recidivas (Hedlund and Fossum, 2008). O prognóstico vai proceder de acordo com o grau de intensidade, tempo e da causa primária, sendo considerado favorável na maioria dos casos quando a causa primária é reconhecida e aperfeiçoada (Ettinger and Feldman, 2004).

\section{Conclusão}

Conclui-se que os prolapsos em geral, caracterizam-se pelo deslocamento do órgão para o exterior da cavidade, mostrando-se edematoso. Os prolapsos mais evidenciados em pequenos animais são o vaginal, uterino e retal, sendo as principais causas hormonais, pós-parto e por tenesmo, respectivamente. $\mathrm{O}$ tratamento de todos é a recolocação do órgão para dentro da cavidade e quando necessária, a ressecção da massa acometida. Na maioria dos casos o prognóstico é favorável, a depender do grau de intensidade, tempo e causa primária do prolapso.

\section{Referências Bibliográficas}

Birchard, S. J. \& Sherding, R. G. 2008. Manual Saunders: clínica de pequenos animais, São Paulo.

Cunha, M. G. M. C., Pelizarri, C., Seraffin, G., Cunha, J. P. M. C. M., Sampaio, K. O., Sousa Filho, R. P. \& Pippi, N. L. 2015. Rectal prolapse secondary to vesicourachal diverticula in a cat. Ciência Animal, 25, 35-39.

Ettinger, S. \& Feldman, E. 2004. Tratado de medicina interna veterinária: doenças do cão e do gato. Guanabara Koogan, Rio de Janeiro.
Hedlund, C. H. \& Fossum, T. W. 2008. Cirurgia do sistema digestório. In: Fossum, T. W. (ed.) Cirurgia de pequenos animais. Elsevier, Rio de Janeiro.

Hedlund, C. S. 2008. Cirurgia dos sistemas reprodutivo e genital. In: Fossum, T. W. (ed.) Cirurgia de pequenos animais. Elsevier, Rio de Janeiro.

Nelson, R. W. \& Couto, C. G. 2015. Medicina interna de pequenos animais. Elsevier Editora, Amsterdan.

Sicard, G. K. \& Fingland, R. B. 2008a. Cirurgia da vagina e da vulva. In: Birchard, S. J. (ed.) Manual Saunders: clínica de pequenos animais. São Paulo.

Sicard, G. K. \& Fingland, R. B. 2008b. Cirurgia de ovário e útero. In: Birchard, S. J. (ed.) Manual Saunders: clínica de pequenos animais. São Paulo.

Slatter, D. H. 2007. Manual de cirurgia de pequenos animais. Manole, São Paulo.

Stone, E. A. 2007. Ovário e útero. In: Slatter, R. D. (ed.) Manual de cirurgia e pequenos animais. Manole, São Paulo.

Wachask, M. J. 2002. Rectal and anal prolapse. In: Tilley, L. P. \& Smith Júnior, F. W. K. (eds.) The 5-minute veterinary consult. Lippincott Williams \& Wilkins, Baltimore, Maryland, USA.

Wintzer, H.-J. 1990. Doenças dos equinos. Manole, São Paulo, Brasil.

\section{Article History:}

Received 11 December 2016

Accepted 17 January 2016

Available on line 4 February 2017

License information: This is an open-access article distributed under the terms of the Creative Commons Attribution License 4.0, which permits unrestricted use, distribution, and reproduction in any medium, provided the original work is properly cited. 